ORIGINAL ARTICLE

\title{
A meta-analysis on intravenous magnesium sulphate for treating acute asthma
}

\author{
D K L Cheuk, T C H Chau, S L Lee
}

Arch Dis Child 2005;90:74-77. doi: 10.1136/adc.2004.050005

See end of article for authors' affiliations

.....................

Correspondence to:

Dr D K L Cheuk

Department of Pediatrics and Adolescent Medicine, Queen Mary Hospital, The University of Hong Kong,

121 Pokfulam Road, Hong Kong; cheukkl@hkusua. hku.hk

Accepted 6 April 2004

\begin{abstract}
Aim: To evaluate the effectiveness of intravenous magnesium sulphate in the treatment of acute asthmatic attacks in children by meta-analysis.

Methods: A systematic and comprehensive search of the literature was performed to identify controlled clinical trials of magnesium sulphate in paediatric acute asthma which evaluated outcomes of hospitalisation or short term pulmonary function tests or symptom scores. Unpublished data were searched by personal contacts with authors and specialists. Two reviewers independently assessed trial qualities and synthesised data. Heterogeneity among studies was evaluated by the Cochrane $Q$ test. Outcome data were pooled by random or fixed effect models depending on presence or absence of heterogeneity.

Results: Five randomised placebo controlled trials involving a total of 182 patients were identified. They compared intravenous magnesium sulphate to placebo in treating paediatric patients with moderate to severe asthmatic attacks in the emergency department, with co-therapies of inhaled $\beta_{2}$ agonists and systemic steroids. The studies were of high quality with results judged to be valid. Four studies showed that magnesium sulphate was effective, while one study found it ineffective. There was no significant heterogeneity in the primary outcome of hospitalisation. In the fixed effect model, magnesium sulphate is effective in preventing hospitalisation (OR $0.290,95 \% \mathrm{Cl} 0.143$ to 0.589 ). The number needed to treat is 4 (95\% Cl 3 to 8 ). Secondary outcomes of short term pulmonary function tests and clinical symptom scores also showed significant improvement.

Conclusion: Intravenous magnesium sulphate probably provides additional benefit in moderate to severe acute asthma in children treated with bronchodilators and steroids.
\end{abstract}

B ronchodilators ( $\beta_{2}$ agonists $)$ and steroids are well established effective treatments for all severities of asthma. ${ }^{1-5}$ However, there are still children with moderate to severe acute asthmatic attacks that may have insufficient improvement, leading to hospitalisation or intensive care unit (ICU) admission, and in the worst cases, severe morbidity and even mortality. Anticholinergics and methylxanthines have controversial efficacies. ${ }^{6-8}$ There is an ongoing need to study new effective bronchodilating agents as additional therapies for relieving moderate to severe asthmatic attacks.

Magnesium sulphate is one of the agents being intensively studied. Although a systematic review published by the Cochrane Collaboration showed that magnesium sulphate is effective in the treatment of severe acute asthma, it included mainly adult studies.' Whether intravenous magnesium sulphate is effective in treating acute asthma in children is still controversial.

We performed a meta-analysis to evaluate the effectiveness of intravenous magnesium sulphate in preventing hospitalisation or ICU admission in children with acute asthmatic attacks, either used alone or in addition to standard therapies.

\section{METHODS}

The search of relevant studies, assessment of trial qualities, extraction of data, synthesis of data by meta-analysis, examination of heterogeneity, and drawing of conclusions were performed by two independent reviewers; discrepancies were resolved by consensus.

\section{Selection criteria}

Inclusion criteria were controlled clinical trials of intravenous magnesium sulphate of any therapeutic dose in children below 18 years of age using outcome measures of hospitalisation, ICU admission, clinical symptom scores, or pulmonary function tests. Both published and unpublished studies were included. There was no language restriction. The exclusion criterion was multiple publications.

\section{Search strategies}

Six databases (Medline, Pubmed, Embase, Cochrane Library, Cochrane Central Register of Controlled Trials, and China Journet Net) were searched under the following terms in the keyword search: "magnesium" and "asthma" and "children". Reference lists and citations of identified studies were located by hand search to explore any published studies missed. Personal contacts with authors and specialists were made as far as possible to obtain unpublished data.

\section{Quality assessment}

The trial quality was assessed using the standard Jadad score ${ }^{10}$ based on the adequacy of randomisation, blinding, and follow up, with the maximum score of 5 points.

\section{Data extraction}

Baseline characteristics of treatment and control groups including age, gender, baseline $\mathrm{SpO}_{2}$, symptom severity, symptom scores, and results of pulmonary function tests (PEFR, $\mathrm{FEV}_{1}$, and FVC) were extracted. The primary outcome measure chosen was rate of hospitalisation or ICU admission, expressed as odds ratio (OR) in treatment compared to control group. Secondary outcome measures were rate of persistent severe bronchoconstriction as indicated by PEFR $<60 \%$ predicted, between group difference in symptom scores and percentage change of pulmonary function tests at the end of the trial. Stratification of outcomes by treatment 
Table 1 Main results of individual studies

\begin{tabular}{|c|c|c|c|c|c|}
\hline Outcome measures & Ciarallo L, 1996 & Devi PR, 1997 & Gurkan F, 1999 & Cariallo L, 2000 & Scarfone RJ, 2000 \\
\hline OR of hospitalisation (95\% Cl) & $\begin{array}{l}0.077 \\
(0.004 \text { to } 1.582)\end{array}$ & $\begin{array}{l}0.235 \\
(0.066 \text { to } 0.841)\end{array}$ & $\mathrm{N} / \mathrm{A}$ & $\begin{array}{l}0.035 \\
(0.002 \text { to } 0.676)\end{array}$ & $\begin{array}{l}0.740 \\
(0.252 \text { to } 2.173)\end{array}$ \\
\hline $\begin{array}{l}\text { OR of persistent PEFR }<60 \% \\
\text { predicted }(95 \% \mathrm{CI})\end{array}$ & $\begin{array}{l}0.165 \\
(0.035 \text { to } 0.785)\end{array}$ & $\begin{array}{l}0.125 \\
(0.021 \text { to } 0.753)\end{array}$ & $\begin{array}{l}0.184 \\
(0.027 \text { to } 1.244)\end{array}$ & N/A & N/A \\
\hline $\begin{array}{l}\text { Percentage change of PEFR } \\
\text { at study end: treatment } v \\
\text { placebo; mean (SD) }\end{array}$ & $\begin{array}{l}59 \%(20 \%) \text { v } 20 \% \\
(11 \%)(p=0.05)\end{array}$ & N/A & $\begin{array}{l}58.4 \%(2.9 \%) v \\
21.8 \%(4.5 \%) \\
(p=0.0001)\end{array}$ & $\begin{array}{l}87 \%(7 \%) \vee 7 \%(2 \%) \\
(p<0.001)\end{array}$ & N/A \\
\hline $\begin{array}{l}\text { Clinical symptom score at } \\
\text { study end: treatment } v \text { placebo; } \\
\text { mean (SD) }\end{array}$ & N/A & $\begin{array}{l}6 \vee 7 \text { (CAS) } \\
(p<0.01)\end{array}$ & $\begin{array}{l}2.5(0.5) v \\
4.3(0.3) \text { (CAS) } \\
(p<0.001)\end{array}$ & $\begin{array}{l}1.1 v 2.4 \text { (CAS) } \\
(p<0.001)\end{array}$ & $\begin{array}{l}5.3(2.8) \vee 6(2.9) \\
(P I)(p=0.001)\end{array}$ \\
\hline Jadad score & 4 & 4 & 4 & 4 & 5 \\
\hline
\end{tabular}

dose, age, and severity class (mild, moderate or severe) for subgroup analyses would be performed if data were available.

\section{Data analyses}

Comprehensive meta-analysis software (available at http:// www.meta-analysis.com) was used for all statistical analyses. Statistical heterogeneity in the outcome measures was assessed using the Cochrane Q test, with $\mathrm{p}<0.1$ considered as significant. The random effect model was used for pooling results if significant statistical heterogeneity was present. Otherwise the fixed effect model was used. Clinical heterogeneity among studies was explored in terms of study design, patients recruited, baseline characteristics, intervention, cotherapies, and outcome measures. Sensitivity analysis was performed by reanalysis, excluding studies with poor quality (Jadad score $<3$ ).

\section{RESULTS}

Under the specified keyword search strategy, 35, 70, 31, 7, 9, and 0 articles were identified in Medline, Pubmed, Embase, Cochrane Library, Cochrane Central Register of Controlled Trials, and China Journet Net respectively. Five independent randomised placebo controlled trials satisfying inclusion criteria were identified. ${ }^{11-15}$ No additional published or unpublished article satisfying inclusion criteria was found on hand search of the citations of these studies and personal contacts.

All trials were carried out at emergency departments comparing intravenous magnesium sulphate to placebo in treating paediatric patients with acute moderate to severe asthmatic attacks, with co-therapies of inhaled $\beta_{2}$ agonists and systemic steroids. All patients who entered the trials had similar severity of asthma as indicated by inadequate response to first line treatment with three doses of $\beta_{2}$ agonists. All the studies were assessed to be of good quality (Jadad score $\geqslant 4$ ).

Table 1 presents the main results of individual studies and the Jadad scores. Since no study mentioned rate of ICU admission, we could only evaluate primary outcome of hospitalisation. Table 2 shows the pooled effect size estimates of primary and secondary outcomes and tests of heterogeneity. The pooled OR estimate for the primary outcome is illustrated by the Forrest plot in fig 1 .

Four of the studies concluded that magnesium sulphate was effective in paediatric acute asthma while one study found it to be ineffective. After pooling the results together, intravenous magnesium sulphate was effective in avoiding hospitalisation. The absolute risk reduction (ARR) for hospitalisation is 0.257 (95\% CI 0.124 to $0.389, \mathrm{p}=0.0001)$. The number needed to treat (NNT) in avoiding hospitalisation is 4 (95\% CI 3 to 8$)$.

The pooled result on short term lung function suggested that there was an approximately $85 \%$ reduction in risk of persistent bronchoconstriction with PEFR $<60 \%$ of predicted values, with all studies showing consistent reduction in risks, although to somewhat different extent.

The pooled result on asthma symptom score also showed significant improvement, with individual studies showing consistent results. It was noted that two different scoring systems were used in the studies, with three of the studies ${ }^{12-15}$ using the clinical asthma symptom score and one using the pulmonary index. However, their results pointed in the same direction, favouring treatment compared to placebo with statistical significance, irrespective of the scoring system used.

No subgroup analysis was performed in different age groups because stratified outcome data were not available in any of the studies. Since all studies included only patients with moderate to severe asthma, we could not evaluate the efficacy of magnesium sulphate in mild asthma. No study compared the effectiveness of different dosages of magnesium sulphate, and therefore we could not further evaluate the dose-response relation. Sensitivity analysis was not performed because of the small number of studies and similarity of trial quality. Possible areas of heterogeneity of the trials are shown in table 3 (available on the $A D C$ website).

Table 2 Pooled effect size estimates and tests of heterogeneity

\begin{tabular}{|c|c|c|c|c|c|c|}
\hline Outcome measures & Model & $\begin{array}{l}\text { Studies included } \\
\text { (reference no.) }\end{array}$ & $\begin{array}{l}\text { Pooled point } \\
\text { estimate }\end{array}$ & $95 \% \mathrm{Cl}$ & p value & $\begin{array}{l}Q \text { test of heterogeneity } \\
p \text { value }(d f)\end{array}$ \\
\hline OR of hospitalisation & $\begin{array}{l}\text { Mantel-Haenszel fixed } \\
\text { effect model }\end{array}$ & $11,12,14,15$ & 0.290 & 0.143 to 0.589 & 0.0006 & $0.13(d f=3)$ \\
\hline $\begin{array}{l}\text { OR of persistent PEFR }<60 \% \\
\text { predicted }\end{array}$ & $\begin{array}{l}\text { Mantel-Haenszel fixed } \\
\text { effect model }\end{array}$ & $11,12,13$ & 0.155 & 0.057 to 0.422 & 0.0003 & $0.97(\mathrm{df}=2)$ \\
\hline $\begin{array}{l}\text { Difference in percentage } \\
\text { improvement of PEFR at } \\
\text { study end }\end{array}$ & $\begin{array}{l}\text { Hedges's random effect } \\
\text { model }\end{array}$ & $11,13,14$ & 8.58 & 0.94 to 16.22 & 0.028 & $<0.0001(\mathrm{df}=2)$ \\
\hline $\begin{array}{l}\text { Difference in clinical symptom } \\
\text { score at study end }\end{array}$ & $\begin{array}{l}\text { Hedges's random effect } \\
\text { model }\end{array}$ & $12,13,14,15$ & 1.33 & 0.31 to 2.36 & 0.011 & $0.0001(d f=3)$ \\
\hline
\end{tabular}




\section{Citation \\ Ciarallo L, 2000 \\ Ciarallo L, 1996 \\ Devi PR, 1997 \\ Scarfone RJ, 2000 \\ Fixed Combined (4)}

\author{
Effect name \\ Hospitalisation \\ Hospitalisation \\ Hospitalisation \\ Hospitalisation
}

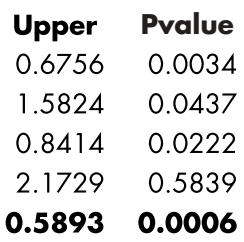

Upper

0.0345

0.0774

0.2350

0.7404

$\mathbf{0 . 2 8 9 9}$
0.0018

0.0038

0.0657

0.2523

0.1426
Pvalue

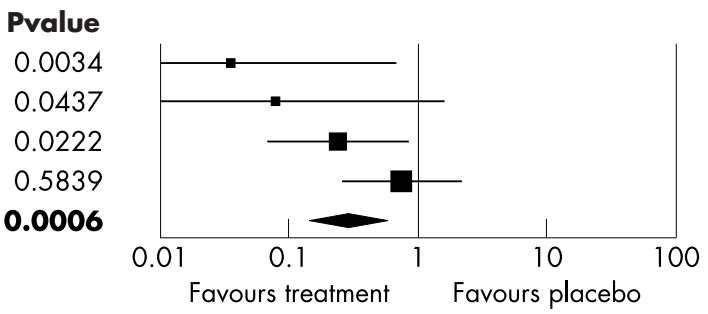

Figure 1 Forrest plot of odds ratio of hospitalisation.

\section{DISCUSSION}

This is the first meta-analysis investigating the effectiveness of intravenous magnesium sulphate in treating acute childhood asthma; it showed a favourable effect. The NNT in avoiding hospitalisation is only four, implying probable high cost effectiveness. In addition to $\beta_{2}$ agonists and systemic steroids, intravenous magnesium sulphate also appears effective in relieving bronchoconstriction and improving asthma symptoms.

Three different single dose regimes of intravenous magnesium were used in the five studies: $25 \mathrm{mg} / \mathrm{kg}$ in two studies, $40 \mathrm{mg} / \mathrm{kg}$ in two, and $75 \mathrm{mg} / \mathrm{kg}$ in one. Interestingly, one study using $25 \mathrm{mg} / \mathrm{kg}$ and another study using $40 \mathrm{mg} / \mathrm{kg}$ magnesium showed a significant reduction in the rate of hospitalisation, whereas the other study using $25 \mathrm{mg} / \mathrm{kg}$ and the study using $75 \mathrm{mg} / \mathrm{kg}$ magnesium reported an insignificant effect on hospitalisation. Whether this inconsistency in dose-response relation is related to intrinsic dosage related effect or confounding factors such as criteria of hospitalisation is not apparent in the current meta-analysis and requires further evaluation in future studies. However, the inconsistent dosage effect might reflect a small sample size of individual studies, resulting in inadequate statistical power to detect a significant effect, especially in view of the consistent trend of reduction in hospitalisation and statistical homogeneity of this primary outcome across studies. Nevertheless, we observed no clear evidence to suggest that higher dosage of magnesium results in better outcomes; further studies are therefore needed to identify the optimal dosage of magnesium with maximal efficacy.

Intravenous magnesium sulphate therapy was well tolerated with only minor side effects reported, such as epigastric or facial warmth, flushing, pain and numbness at infusion site, dry mouth, and malaise. ${ }^{12}{ }^{16}$ It is generally safe to be used in children with moderate to severe acute asthma, although

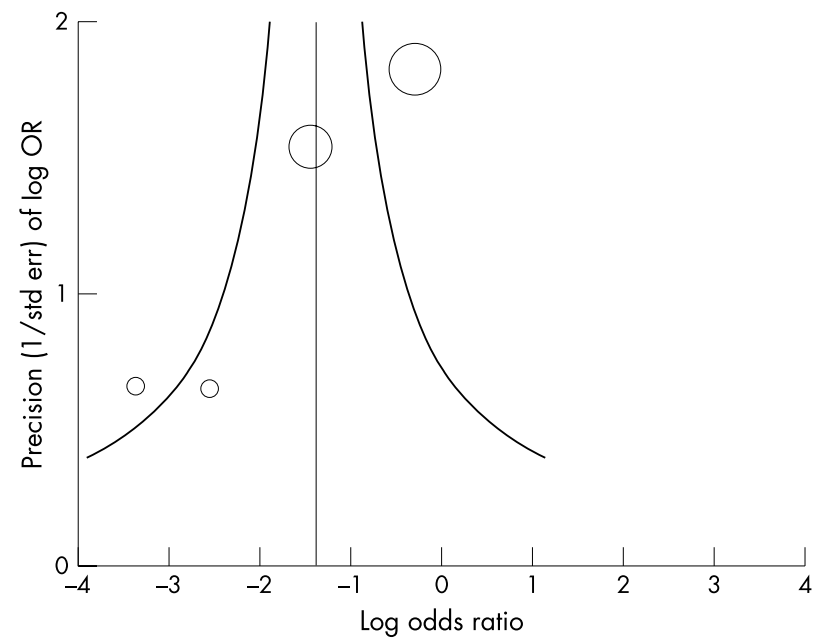

Figure 2 Funnel plot of precision by effect size. rare adverse effects might have escaped detection in the small samples.

The mechanism of action of magnesium sulphate is not clearly defined. Magnesium ion decreases the uptake of calcium by bronchial smooth muscle cells, which in turn leads to bronchodilation. ${ }^{17}$ Magnesium may also have a role in inhibiting mast cell degranulation, thus reducing inflammatory mediators such as histamine, thromboxanes, and leukotrienes. ${ }^{17}$ In addition, magnesium inhibits the release of acetylcholine from motor nerve terminals and depresses the excitability of muscle fibre membranes. ${ }^{18} 19$

There were several limitations in the current meta-analysis. Firstly, studies were heterogeneous with respect to patient inclusion criteria, baseline characteristics, magnesium sulphate dosage, co-therapies, and outcome measures, although there was no statistically significant heterogeneity in the primary outcome. Hence care should be taken in applying the pooled result to individual patients in clinical practice. Secondly, the total number of patients involved in all the studies combined is still relatively small. The study by Scarfone and colleagues ${ }^{15}$ comprised about $30 \%$ of patients and concluded that magnesium is ineffective. Two of the five studies reporting effectiveness of magnesium had the same first author ${ }^{11}{ }^{14}$ and involved one third of the total number of patients. Thirdly, the pooled effect estimate, though significant statistically, was not precise as only a few studies have been performed. Fourthly, subgroup analysis was not possible because stratification of outcomes or raw data were not available. Finally, publication bias might be present as suggested by funnel plot asymmetry (fig 2). Unpublished negative studies might have been missed.

\section{Conclusion}

Based on existing data, intravenous magnesium sulphate is likely to be effective in avoiding hospitalisation and improving bronchoconstriction and clinical symptoms of moderate to severe acute asthma in children, when added to standard therapies of inhaled bronchodilators and systemic steroids.

Further studies are needed to evaluate the effectiveness of intravenous magnesium sulphate in different severity classes of asthma and in patients of different age groups. Studies should also aim at further defining the indications, possible contraindications, and optimal dosage of intravenous magnesium sulphate.

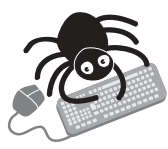

Table 3 is available on the ADC website (www. archdischild.com/supplemental)

\section{Authors' affiliations \\ D K L Cheuk, S L Lee, Department of Pediatrics and Adolescent Medicine, The University of Hong Kong \\ T C H Chav, Hong Kong Baptist University}




\section{REFERENCES}

1 Rowe BH, Edmonds ML, Spooner $\mathrm{CH}$, et al. Evidence-based treatments for acute asthma. Respir Care 2001;46:1380-90.

2 Edmonds ML, Camargo CA, Pollack CV, et al. Early use of inhaled corticosteroids in the emergency department treatment of acute asthma. Cochrane Database of Systematic Reviews 2003;1.

3 Rowe BH, Spooner C, Ducharme FM, et al. Early emergency department treatment of acute asthma with systemic corticosteroids. Cochrane Database of Systematic Reviews 2003; 1

4 Smith M, Iqbal S, Elliott TM, et al. corticosteroids for hospitalized children with acute asthma. Cochrane Database of Systematic Reviews 2003;1.

5 Manser R, Reid D, Abramson M. Corticosteroids for acute severe asthma in hospitalized patients. Cochrane Database of Systematic Reviews 2003;1.

6 Plotnick LH, Ducharme FM. Combined inhaled anticholinergic and beta2agonists for initial treatment of acute asthma in children. Cochrane Database of Systematic Reviews 2003;1.

7 Mitra A, Bassler D, Ducharme FM. Intravenous aminophylline for acute severe asthma in children over 2 years using inhaled bronchodilators. Cochrane Database of Systematic Reviews 2003;1.

8 Parameswaran K, Belda J, Rowe BH. Addition of intravenous aminophylline to beta2-agonists in adults with acute asthma. Cochrane Database of Systematic Reviews 2003;1.

9 Rowe BH, Bretzleff JA, Bourdon C, et al. Magnesium sulfate for treating exacerbations of acute asthma in the emergency department. Cochrane Database of Systematic Reviews 2003;1.
10 Jadad AR, Moore RA, Carroll D, et al. Assessing the quality of reports of randomized clinical trials: is blinding necessary? Controlled Clinical Trials 1996;17:1-12.

11 Ciarallo L, Sauer AH, Shannon MW. Intravenous magnesium therapy for moderate to severe pediatric asthma: results of a randomized, placebocontrolled trial. J Pediatr 1996;129:809-14.

12 Devi PR, Kumar L, Singhi SC, et al. Intravenous magnesium sulfate in acute severe asthma not responding to conventional therapy. Indian Pediatr 1997;34:389-97.

13 Gurkan F, Haspolat K, Bosnak M, et al. Intravenous magnesium sulfate in the management of moderate to severe acute asthmatic children non-responding to conventional therapy. Eur J Emerg Med 1999;6:201-5.

14 Ciarallo L, Brousseau D, Reinert S. Higher-dose intravenous magnesium therapy for children with moderate to severe acute asthma. Arch Pediatr Adolesc Med 2000;154:979-83.

15 Scarfone RJ, Loiselle JM, Joffe MD, et al. A randomized trial of magnesium in the emergency department treatment of children with asthma. Ann Emerg Med 2000;36:572-8.

16 Monem GF, Kisson N, DeNicola L. Use of magnesium sulfate in asthma in childhood. Pediatr Ann 1996;25:138-44.

17 Skobcloff EM. An ion for the lungs. Acad Emerg Med 1996;3:1082-5.

18 Del Castillo J, Engback L. The nature of the neuromuscular block produced by magnesium. J Physiol 1954;124:370-84.

19 McLean RM. Magnesium and its therapeutic uses: a review. Am J Med 1994;96:63-76.

\section{IMAGES IN PAEDIATRICS}

\section{Running for the line}

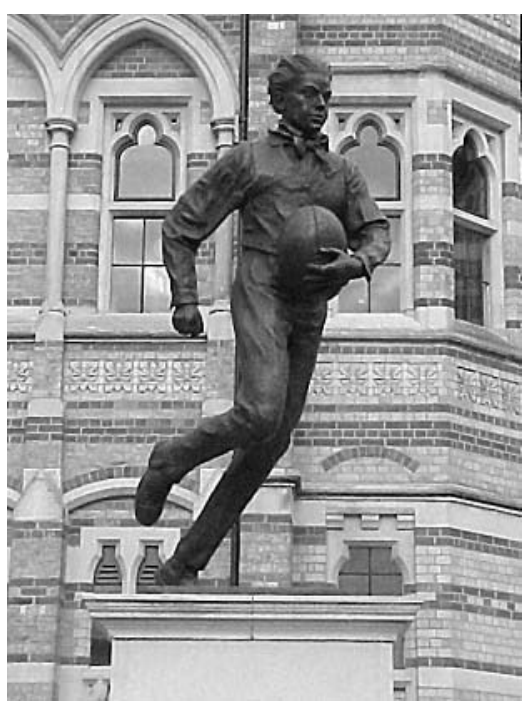

n 1823, while playing a game of soccer at school, William Webb-Ellis broke the rules. He picked up the ball and ran the whole length of the pitch with it. This memorial statue is in the town of Rugby, which gave its name to the game that his impulsive act inspired.

Most paediatricians get referrals about children with behaviour problems. Some referrals are justified, but in our experience they often stem from the hope that some "physical" cause will be found, one which is treatable if not curable by a tablet.

Do these children need to see a doctor? There is rarely a physical cause. Of course we need to consider conditions such as ADHD, but these are a minority.

A child's behaviour can be uncomfortable for adults. If we were children now, how many of us would end up being referred for the same "behaviour difficulties" we as doctors are asked to consult on. As Webb-Ellis showed, the ability to think and act "outside the box" may have remarkable results. It is a shame if children cannot be allowed to do anything different without someone deciding this is a "medical problem". We should encourage creativity within our children and resist the medicalisation of childhood.

C Essex

Gulson Hospital, Coventry CV1 2HR, UK

A N Williams

Child Development Centre, Northampton General Hospital, Northampton NNI, UK

Correspondence to: Dr C Essex, Consultant Neurodevelopmental Paediatrician, Gulson Hospital, Coventry CV1 2HR, UK; room101@ntlworld.com 